\title{
Doll Play narratives about starting school in children of socially anxious mothers, and their relation to subsequent child school-based anxiety
}

Article

Accepted Version

Pass, L., Arteche, A., Cooper, P., Creswell, C. and Murray, L. (2012) Doll Play narratives about starting school in children of socially anxious mothers, and their relation to subsequent child school-based anxiety. Journal of Abnormal Child Psychology, 40 (8). pp. 1375-1384. ISSN 0091-0627 doi: https://doi.org/10.1007/s10802-012-9645-4 Available at https://centaur.reading.ac.uk/27904/

It is advisable to refer to the publisher's version if you intend to cite from the work. See Guidance on citing.

To link to this article DOI: http://dx.doi.org/10.1007/s10802-012-9645-4

Publisher: Springer

Publisher statement: The original publication is available at www.springerlink.com

All outputs in CentAUR are protected by Intellectual Property Rights law, including copyright law. Copyright and IPR is retained by the creators or other copyright holders. Terms and conditions for use of this material are defined in the End User Agreement. 


\section{www.reading.ac.uk/centaur}

\section{CentAUR}

Central Archive at the University of Reading

Reading's research outputs online 
Doll Play narratives about starting school in children of socially anxious mothers, and their relation to subsequent child school-based anxiety Laura Pass ${ }^{1}$, Adriane Arteche ${ }^{1}$, Peter Cooper $^{1}$, Cathy Creswell $^{1}$, Lynne Murray $^{1} *$

${ }^{1}$ School of Psychology

University of Reading

*Corresponding author

Author Note

The research was funded by ESRC and MRC grants to Lynne Murray and Peter Cooper.

Laura Pass was supported by an ESRC studentship. We thank Liz Schofield, Sarah Shildrick and Melanie Royal-Lawson for assistance with data collection and coding.

Correspondence concerning this article should be sent to Lynne Murray, Winnicott Research Unit, School of Psychology, University of Reading, RG6 6AL

Tel: 01183786667

Fax: 01183786665

Email: 1ynne.murray@reading.ac.uk 


\begin{abstract}
Background: Child social anxiety is common, and predicts later emotional and academic impairment. Offspring of socially anxious mothers are at increased risk. It is important to establish whether individual vulnerability to disorder can be identified in young children. Method: The responses of 4.5 year-old children of mothers with social phobia $(N=62)$ and non-anxious mothers $(N=60)$ were compared, two months before school entry, using a Doll Play (DP) procedure focused on the social challenge of starting school. DP responses were examined in relation to teacher reports of anxious-depressed symptoms and social worries at the end of the child's first school term. The role of earlier child behavioral inhibition and attachment, assessed at 14 months, was also considered.

Results: Compared to children of non-anxious mothers, children of mothers with social phobia were significantly more likely to give anxiously negative responses in their school DP $(\mathrm{OR}=2.57)$. In turn, negative DP predicted teacher reported anxious-depressed and social worry problems. There were no effects of infant behavioral inhibition or attachment. Conclusion: Vulnerability in young children at risk of anxiety can be identified using Doll Play narratives.
\end{abstract}

Key words: social phobia, child anxiety, play narratives, school adjustment. 
Doll Play narratives about starting school in children of socially anxious mothers, and their relation to subsequent child school-based anxiety

Anxiety, including social anxiety, is common and persistent in young children (Cartwright-Hatton, McNicol, \& Doubleday, 2006), and is associated with a range of adverse sequelae. The question of whether child vulnerability may be apparent before the development of serious clinical problems is of theoretical importance in understanding the development of disorder, and clinically important for enabling early intervention. A number of etiological factors are likely to be involved in the development of anxiety (Rapee, Schniering, \& Hudson, 2009). Among these, parental, and particularly maternal anxiety have been found to elevate risk for child disorder (Cooper, Fearn, Willetts, Seabrook, \& Parkinson, 2006). Notably, such increased child risk may be particularly raised where mothers have either social phobia or generalised anxiety disorder (Schreier, Wittchen, Hofler, \& Lieb, 2008). While genetic and family aggregation data do not suggest a one-to-one correspondence between parental and child anxiety (Hettema, Neale, \& Kendler, 2001) there is, nevertheless, evidence for some degree of specificity in the transmission of social phobia (Cooper et al., 2006; Lieb et al., 2000).

In addition, certain child characteristics may increase risk of developing anxiety, namely, insecure attachment (Warren et al., 1997), and behavioral inhibition (BI) (Biederman et al., 1993), i.e., fear of the unfamiliar and avoidance of novelty (Kagan, Reznick, \& Snidman, 1987). Aside from their possible direct links to subsequent child anxiety, and in line with the 'differential susceptibility' hypothesis proposed by Belsky, Hsieh and Crnic (1998), it is also possible that insecurity of attachment and an inhibited temperament may each make a child more vulnerable to the effects of environmental risk factors, including parental anxiety. For example, the insecure child may lack the resilience to cope with the challenges posed by the parental disorder (Arend, Gove, \& Sroufe, 1979), or the inhibited 
child may be highly susceptible to registering cues to threat expressed by an anxious parent. Degnan, Almas and Fox (2010) refer to these child characteristics as the beginning of a 'vulnerability pathway', whereby environmental influences such as parenting can subsequently affect the developmental trajectory towards (or away from) anxiety. Thus, characteristics such as BI may only be associated with later internalizing problems in the context of additional adversity such as parenting difficulties (e.g., Hane, Cheah, Rubin \& Fox, 2008) and psychopathology.

While it may be important to identify early signs of child anxiety, or vulnerability to disorder, doing so presents some challenges. First, relying on parental report can lead to bias (Carter, Briggs-Gowan, \& Ornstein Davis, 2004), especially in the context of parental psychopathology (Najman et al., 2001). Second, and particularly when considering internalising problems like anxiety, informants, including parents, may have insufficient access to the child's internal world (Warren, Oppenheim, \& Emde, 1996).

These considerations underline the importance of including child self-report; however, this itself presents methodological problems, especially with young and anxious children. These include undeveloped vocabulary and narrative skills, denial of problems, and the influence of social desirability (Beidel \& Turner, 1998; Pina, Silverman, Saavedra, \& Weems, 2001). Thus, while there have been important advances in structured interviewbased assessments (e.g., the PAPA; Egger \& Angold, 2004), other child-directed approaches should also be considered.

\section{Use of doll play as a tool}

One methodology for gaining insight into children's experience and perceptions is Doll Play (DP), or play narratives. In comparison to young children's purely verbal reports, portrayals of feelings and behavior through DP may be more sophisticated (Woolgar, 1999). Further, the use of props such as dolls may help overcome children's developmental 
constraints. Thus, while such techniques can elicit useful information from children of almost all ages, they stand to be of particular value for young children (Marshall \& Katz, 1992). Importantly, children's ways of representing their relationships, beliefs and expectations in DP reflect not only their actual experience, but also their 'construction of reality'(Holmberg, Robinson, Corbitt-Price, \& Wiener, 2007). Since children are active participants in their social environment, and influence their own development and knowledge acquisition (Ding, 2005), knowing how they perceive their own reality is important in understanding their experience of difficulties.

There is a long clinical tradition of using symbolic play to access young children's inner worlds (Alvarez \& Phillips, 1998), and in the last twenty years there has been considerable research interest in DP as a means of examining children's experience. A number of narrative DP techniques have been developed (Bettmann \& Lundahl, 2007), many of which focus on attachment representations; the most widely applied being the MacArthur Story Stem Battery (MSSB; Bretherton \& Oppenheim, 2003). Such approaches have been successfully used to assess dimensions of child behavior such as internalising and externalising problems (Laible, Carlo, Torquati, \& Ontai, 2004; Warren, et al., 1996).

In addition to the above, largely attachment-oriented play narratives, and their relation to relatively broad measures of child functioning, recent research has examined DP in relation to distinct clinical populations. In these studies, narrative stems have been developed around situations that are specific to each problem, and have elucidated relevant child vulnerability (e.g., recurrent abdominal pain; Ramchandani, Murray, Romano, Vlachos, \& Stein, 2011). Two studies have focused on child anxiety. In that of Warren, Emde and Sroufe (2000), 12 stems from the MSSB were augmented by a further four concerning potentially anxiety-provoking situations, and in that of Dodd, Hudson, Morris and Wise (2011), three anxiety-relevant, ambiguous scenario narrative stems were used. In addition, 
each study used coding schemes designed to identify child anxiety-relevant representations, i.e., negative expectations (concerning self-competence, parental support, and separation difficulties), and threat interpretation, respectively; and both included consideration of child inhibited temperament. The study by Warren et al. (2000) found that overall negative expectations in child DP narratives at five years predicted anxiety one year later, as assessed through teacher/parent report, although no effects of child temperament were identified. Dodd et al. (2011) similarly found no effects of child inhibition, but did find child threat interpretations to be associated with both current, and subsequent child anxious symptoms (although not diagnoses, or longer term symptoms).

\section{The current study}

Together, the recent findings outlined above suggest the adaptation of narrative DP assessments to disorder-relevant scenarios may be a particularly fruitful direction for clinical research. We therefore used this approach in the context of a prospective longitudinal study of children of socially anxious vs. non-anxious mothers that had involved assessments through infancy. Our aims were three-fold: the first was to examine the question of vulnerability to social anxiety in socially anxious mothers' children. Accordingly, we constructed our DP narrative stems around a real-life, potential social challenge. Given that anticipation of threat is of central importance in models of the development and maintenance of child anxiety (e.g., Kendall, 2006), and therefore representations of future events may be particularly likely to elucidate responses reflecting vulnerability, we selected the imminent event of starting school (which, in the UK, occurs around the time of the child's fifth birthday) as the focus for our assessment. Here, children face several new challenges, including separation from their caregiver, academic demands and, not least, social interaction with other children and unfamiliar adults. Studying how children perceive the demands of starting school may therefore provide an important opportunity to investigate vulnerability in 
the face of a potentially anxiety-provoking, ecologically valid, social event. Given the range of potential social demands children face at this time, and in line with previous studies of narrative play in relation to child anxiety in general, we developed a number of specific DP stems within the overall starting school theme, in tandem with a coding scheme that included key responses relevant to anxiety, and particularly social anxiety. These included representations of maternal negative responses to school, fear of performing in public and of others' negative evaluation, and social avoidance, as well as codes similar to those employed by Warren, and Dodd and colleagues concerning dependency/separation problems and threat interpretations.

Our second aim was to investigate the role of insecure attachment and BI, capitalising on previous assessments of these behaviors in infancy. Thus, we examined their direct effects on child DP responses, as well as the question of whether they may each have made the child more vulnerable to any effects of maternal social anxiety (as the differential susceptibility hypothesis would suggest). In line with previous research (e.g., Hill et al., 2007; Murray et al., 1999; Warren et al., 2000), we also examined the role of other child characteristics that might affect DP, and therefore potentially confound the interpretation of any effects of maternal social anxiety; these were gender and, given the mainly cognitive demands of the task, verbal (rather than overall) IQ.

Finally, we aimed to determine whether negativity in DP narratives predicted subsequent child behavior at school and, specifically, anxious-depressed symptoms and social worries, as reported by their teacher. When investigating this predictive utility of children's DP, we considered it important to control for the same child behavior at baseline. Since this was conducted before the child attended school, only maternal reports were available, and these were therefore used.

\section{Method}




\section{Sample}

Ninety-six mothers with Social Phobia (SP) and 94 non-anxious controls were originally recruited in pregnancy as part of a longitudinal study concerning maternal social anxiety and child development. They were followed up, with their infants, through the first two years (see Murray, Cooper, Creswell, Schofield, \& Sack, 2007; Murray et al., 2008). Of the index mothers recruited, 30 had a secondary diagnosis of GAD, and five mothers, including one in the control group, had a diagnosis of depression. At child age 4.4 years, two-three months before the child was due to start school, mothers were re-contacted: 77 in the SP group and 67 controls were followed up (i.e., $80.2 \%$, and $71.3 \%$ of those recruited). Mothers gave written informed consent. The study was approved by the Berkshire Research Ethics Committee and the University of Reading Ethics and Research Committee.

\section{Procedure}

At follow-up, mother-child pairs visited the University research unit on two occasions. First, two months before the child started school, child DP narratives were assessed, and the mother completed a report concerning child anxiety-depression. Second, after one school term, the child's verbal IQ was assessed, and the mother was interviewed to assess her mental state, and she completed self-report anxiety questionnaires. Teacher reports on the child were also obtained at this time. Child assessments were conducted by trained researchers who were blind to maternal group. Similarly, assessment of maternal psychiatric state was completed by a trained researcher, blind to all information concerning the child.

Prior to the DP, the researcher confirmed school details with the mother. She then took the child into a comfortable room and showed the child a model school (see Figure 1) placed upon a table, at which the child was invited to sit. A model dolls' house was also placed on the table $0.5 \mathrm{~m}$ from the school. The researcher explained that she knew that the child was shortly due to start school, and that they were going to pretend that the model 
school was the child's real school and that it was the child's first day. The researcher familiarized the child with the school lay-out (cloakroom, classrooms, bathroom and playground, populated by a number of dolls representing other children). The child was then invited to choose doll figures from a selection to represent themselves, their mother and teacher. The researcher then administered a series of story stems, using a standardized script and doll enactments. Four stems concerned school and culminated in an event that could potentially provoke anxiety, and particularly social anxiety. Stem 1 concerned arriving at school, and then the mother leaving; Stem 2 concerned a social performance in class, where the child character was asked by the teacher to 'show your drawing'; Stems 3 and 4 each concerned potential fear of evaluation:- For Stem 3, after 'show your drawing', some other children giggle; for Stem 4 other children are laughing in the playground (adapted from Barrett, Rapee, Dadds, \& Ryan's (1996) ambiguous scenarios used in the context of child anxiety). The final stem shifted to the dolls' house and ended on a clearly positive note (this stem was not coded). After each story stem, as in the MSSB methodology (Bretherton \& Oppenheim, 2003), the researcher invited the child to describe what happened next, moving the dolls if they wished. Children were also asked how they would feel, and why. For Stem 1, the same questions were posed about the mother. Standard prompts were used if the child was unresponsive, however, the researcher did not otherwise assist the child in telling the story. No time limit was placed on the play, and sessions generally lasted 10 minutes. Play was terminated if the child wished to finish (the manual for the task is available from LM).

\section{Measures used in the current paper}

Maternal anxiety: This was assessed at recruitment and followed up by the Structured Clinical Interview for DSM-IV (SCID; First, Spitzer, Gibbon, \& Williams, 2002), affective disorder section, administered by a trained researcher. This is a standardised diagnostic interview, with good reliability and validity. Mothers were classified at recruitment as 
having a primary diagnosis of DSM-IV generalised social phobia (index group), or else no current or previous anxiety (control group). Secondary diagnoses of GAD were also noted, as was depression. Maternal interviews were audio-taped, and discussed with senior clinicians to confirm diagnoses. Twenty randomly selected tapes were independently rated to confirm reliability (primary diagnoses $\kappa=.89$ ). Mothers also completed the Social Phobia Scale and Social Interaction Anxiety Scale (SPS, SIAS; Mattick \& Clarke, 1998) at recruitment and follow up. Both questionnaires have good reliability and validity (Mattick \& Clarke, 1998).

Socio-economic status. Maternal socio-economic status (SES) was assessed using the National Statistics Socio-Economic Classification (NS-SEC; HMSO, 2005), where classes 13 were categorised as high SES.

Child measures. Infancy. Behavior inhibition (BI). This was assessed as present/absent at 14 months according to the paradigm of Kagan et al. (1987) in which latencies to approach, and fear or distress towards novel stimuli are assessed (see Murray et al., 2008, for details). Trained researchers scored the tapes; 20, selected at random, were independently scored by both $(\kappa=1)$.

Attachment (14 months). Attachment was assessed using The Strange Situation Procedure (Ainsworth, Blehar, Waters, \& Wall, 1978), a widely used and well-validated measure. Twenty videotapes of the procedure were scored by two trained raters $(\mathrm{K}=.86)$, and, due to small numbers in insecure subgroups, infants were classified as secure, or insecure (avoidant, resistant or disorganized) (Ainsworth et al., 1978; Main \& Solomon, 1990).

\section{Four-Year Assessments}

Child doll play. A coding scheme was designed specifically for this study, and comprised 15 binary variables relevant to child anxiety, with particular relevance to social 
anxiety; all were stem-specific, apart from the last three which related to the child's entire doll play. As for the design of the DP scenarios, the codes for the child's responses were also predetermined on the basis of the literature on child social anxiety, including DSM-IV symptoms; the criteria for each code in terms of child responses were also specified according to the literature, with more detailed refinements being made by the research team on the basis of pilot tapes. The 15 codes were as follows:

Stem 1, Arriving at school and mother leaving:

1) Dependency on mother, e.g., enacts self as standing very close to mother in playground, away from other doll characters and with no social interaction with them, and following mother out of gates when she leaves.

2) Negative depiction of school experience, e.g., reports hostility from the other children, such as being laughed at or pushed when mother leaves.

3) Maternal negative response to school, e.g., no social engagements shown and described as feeling sad when she goes home because nobody is with her.

4) Avoidance of starting school topic. Child requires repeated (three or more) prompts to provide an answer, or is unable to provide an answer (N.B. this does not comprise non-compliance due to being off-task). A criterion of three prompts was chosen, as a reminder prompt was deemed a normal procedure to help ensure children were engaging with the task.

Stem 2, Showing drawing:

1) Performance negativity. Either a negative emotional response to being asked to show their drawing (e.g., says they feel sad), or reports expectation of a hostile response from other children (e.g., saying the other children will not like it).

2) Performance avoidance. Depicts marked reluctance to show drawing, or refusal.

3) Avoidance of performance topic. As for Stem 1, 4). 
Stem 3, Children giggling during child showing drawing:

1) Anxious interpretation of performance evaluation, e.g., states the children are giggling because they didn't like the picture.

2) Avoidance of evaluation of performance topic: as for Stem 1, 4).

Stem 4, Children laughing in playground:

1) Anxious interpretation of others' behavior/ evaluation of self, e.g., child reports they are laughing because they don't like her or they think she looks silly.

2) Negative response to others' social behaviour. Pervasive reluctance to engage and/or avoidance and lack of any appropriate, pro-social or adaptive behavior, e.g., child says she doesn't like playing with the children, and leaves the school.

3) Avoidance of topic of others' social behavior: as for Stem 1, 4).

Non-stem-specific responses:

1) Unsolicited mention of mother/father/home where mother is not present e.g., in response to children giggling in the classroom, child says it's time to go home and their mother comes to pick them up.

2) Use of anxiety-related words in child's narration, e.g., shy, scared, worried, even if not describing self.

3) Signs of non-verbal anxiety in response to Stems, e.g., fingernail biting, repetitive touching of face/hair.

The child's DP was coded using both transcripts and videos, by two trained researchers blind to maternal group and all information concerning the child. A random sample of 20 cases was used to establish inter-rater reliability for the 15 coded DP variables (mean $\kappa=.92$, range $.86-1)$ with approximately 20 hours being required for reliability training. Next, following a similar procedure to Warren et al. (2000), an 'Anxiously Negative' response aggregate was calculated to identify children with pervasive expressions 
of anxiety of a predominantly social form. For each child, the number of these anxiously negative responses was calculated as a proportion of the number of codable responses made $($ mean $=14, S D=1.09$, range $8-15)$. This proportion was then dichotomized to characterize children whose overall DP reflected a high degree of anxious negativity (at least $40 \%$ responses), this defined the highest scoring $25 \%$ of children. Among community populations, this $25 \%$ / 75\% dichotomous split enables identification of individuals of particular concern (Farrington \& Loeber, 2000).

Child Verbal IQ. This was assessed using a pro-rated verbal IQ score (comprising Comprehension, Arithmetic, Vocabulary and Similarities) from the revised Wechsler Preschool and Primary Scale of Intelligence (WPPSI-R) (Wechsler, 1990).

Teacher reported child anxiety. (a) A dichotomous measure of teacher-rated symptoms was obtained to identify children with borderline/clinically significant problems on the anxious-depressed subscale of the Child Behavior Checklist Caregiver-Teacher Report Form (C-TRF) 1 1/2 - 5, a well validated and reliable measure of child behavior (Achenbach \& Rescorla, 2000). (b) A continuous measure of social worries was also used, namely, the teacher version of the Social Worries Questionnaire (SWQ; Spence, 1995). This comprises eight items relating to avoidance or worrying about social situations in the school context (e.g., 'Avoids or gets worried about speaking in class'). The SWQ has shown good reliability and validity in a slightly older sample (Spence, 1995). Similar means and standard deviations were found in the current sample, and high internal consistency $(\alpha=0.94)$ and four month test-retest reliability $\left(\mathrm{r}_{\mathrm{s}}=.67, p<.001\right)$ were also observed.

Mother-rated child baseline anxiety. Mothers completed the anxious-depressed subscale measure of the Child Behavior Checklist (CBCL) 11/2- 5 (Achenbach \& Rescorla, 2000), which parallels the teacher-completed measure. As for the teacher scale, the dichotomous score was used. 


\section{Data analytic strategy}

First, the effects of potential covariates (gender, attachment, BI, verbal IQ) on DP anxious negativity were assessed, using logistic regression. Then, the effect of maternal social phobia on child DP was investigated, controlling for any significant $(p<.05)$ covariates, using logistic regression. Logistic regression was also used to examine the moderating effects of insecure infant attachment and BI on group in predicting DP, with significant covariates (if not included in the specific moderation) also being taken into account. Following this, the effect of child DP on teacher rated school-based anxiety (anxious-depressed symptoms and social worries), controlling for maternally rated child anxious-depressed symptoms at baseline, was assessed using logistic regression or ANOVA, as appropriate.

\section{Results}

Sixty-two index and 60 comparison children provided DP data (seven did not complete the assessment, 15 children were excluded (e.g., because of having already started school, unusable data)). There were no differences in demographic or child characteristics between those with and without DP (all $p$ 's $>.1$ ), and nor did index and control groups with DP differ on these variables, including BI and attachment (all $p$ 's $>.1$, see Table 1). Consistent with other longitudinal research (e.g., Degonda \& Angst, 1993), 36 (58\%) of index group mothers no longer met full DSM-IV criteria for a diagnosis of social phobia at follow up. Nevertheless, these latter mothers, compared to controls, still had more social anxiety symptoms on the SPS (mean $=18.26$ and 7.32 for index and control mothers respectively, $F\left(1,92=28.06, p<.0001, \mathrm{y}^{2}=.23\right)$ ), and more social interaction difficulties on the SIAS (means $=32.43$ and 13.08 respectively, $\left(F(1,92)=102.08, p<.0001, \mathrm{y}^{2}=.53\right)$ ). These findings are in line with suggestions that social anxiety symptoms tend to be chronic, even when not meeting full diagnostic criteria (Wittchen \& Fehm, 2003). Mothers were 
therefore retained in their original groupings but, as an additional check, analyses were also conducted in which children of these sub-clinical index group mothers were compared to controls. We also checked whether results for children of mothers who had a secondary diagnosis of GAD ( $N=21$ in this followed up sample) differed from those of mothers with social phobia alone $(N=41)$. Results for children of mothers with secondary diagnoses of depression were not examined separately, due to the small number $(N=3$ in the followed up sample).

\section{Effects of child characteristics on DP}

Neither verbal IQ, attachment, nor BI significantly predicted child DP anxious negativity (all $p$ 's $>.1$, range .40- .69); however, there was a significant effect of child gender, with boys being more likely to give anxiously negative DP responses than girls (34.5\% and $16.4 \%$, respectively, and see Table 2$)$. Therefore, gender was included as a covariate in the following analyses.

\section{Maternal group effect on child DP}

While in the sample as a whole, $25 \%$ of children showed anxiously negative DP, the proportions differed between maternal groups (32.3\% of index group compared to $16.7 \%$ of control group). After controlling for child sex, children of index mothers were found to be significantly more likely to give anxiously negative DP responses than children of control mothers (see Table 2). The effect of maternal group on DP responses was also significant without including gender as a covariate $(B=0.87$, Wald $=0.69, p=.049, \mathrm{OR}=2.38, \mathrm{CI}=$ 1.01 -5.64). Moreover, when comparing children of index mothers who no longer met full criteria for social phobia at the DP assessment, to control children, this effect of maternal group remained significant $(p<.05)$. There was no significant difference found between children of mothers with a diagnosis of both GAD and social phobia, and children of mothers with social phobia alone $(p>.1)$. 
Neither attachment nor BI moderated the effect of maternal group on child DP anxious negativity (group $\mathrm{x}$ attachment: $B=.98$, Wald $=0.85, p>.1, \mathrm{OR}=2.67, \mathrm{CI}=0.33$ 21.60; group x BI: $B=1.57$, Wald $=1.50, p>.1, \mathrm{OR}=4.79, \mathrm{CI}=0.39-58.90$ ).

Table 2 about here

\section{Child DP effects on teacher reports}

We next examined the effects of child DP on teacher rated school-based problems, i.e., the C-TRF anxious-depressed subscale category, and continuous SWQ scores (child BI, attachment and gender were not included as covariates, as they were not associated with teacher reports (all $p$ 's >.05)). Children with anxiously negative DP were 6.87 times more likely to score in the borderline/clinical range for anxious-depressed symptoms (14.8\%) than children with less anxiously negative DP (2.5\%), and they also had higher SWQ scores (mean $=5.39, S D=5.39$, and mean $=3.34, S D=3.97$, respectively) (Anxious-depressed category: $B$ $=1.93, \mathrm{Wald}=4.61, p=.03 . \mathrm{OR}=6.87, \mathrm{CI}=1.18-39.92 ;$ SWQ scores: $F(1,111)=4.66, p=$ $\left..03, \mathrm{y}^{2}=.04\right)$. When maternal ratings of anxious-depressed symptoms on the CBCL at baseline were controlled for, the pattern of results was unchanged, although that for the SWQ was reduced to marginal significance (DP to anxious-depressed C-TRF category: $B=1.86$, Wald $=4.23, p=.04, \mathrm{OR}=6.42, \mathrm{CI}=1.09-37.68 ;$ DP to $\operatorname{SWQ}\left(F(1,106)=3.75, p=.06, \mathrm{y}^{2}=\right.$ $.03)$.

\section{Discussion}

Using a Doll Play narrative technique focused on the potentially challenging social event of starting school, we found four-five year-old children of mothers diagnosed with social phobia during the child's lifetime, to be more likely to provide highly anxiously 
negative DP responses than children of non-socially anxious mothers. Our study thus highlights the value of obtaining such child reports of their experiences, and shows how accessing the child's perspective can enrich our understanding of the nature of intergenerational transmission of emotional disturbance. Of particular note was our finding that child anxiously negative DP responses about starting school predicted teachers' ratings of anxious-depressed symptoms and social worries in the school context after one term, even when accounting for maternally-rated child symptoms at baseline. The possibility that child vulnerability may be evident before the emergence of significant clinical problems is of both theoretical and clinical importance; and the current study endorses the use of DP as a means of elucidating such vulnerability.

In contrast to the role of maternal social phobia, no associations were identified between earlier child BI and DP anxious negativity, consistent with the findings of Warren et al. (2000), and Dodd et al. (2011). One possible reason for this lack of association may be that, being an essentially behavioural reaction to the unfamiliar or novel, BI is fundamentally distinct from the more cognitively based responses we examined through DP, where the child was asked to make judgments concerning a future event. It is also worth noting that, at best, only modest associations between BI and social anxiety have been found in previous research (Degnan et al., 2010), suggesting that our findings are not necessarily surprising.

Alternatively, it is possible that children had not remained inhibited from infancy through the preschool years. Indeed, previous research suggests that for those not falling at either extreme, there may be a lack of inhibition status stability (Kagan, Snidman, Zentner, \& Peterson, 1999), with up to almost half of children showing changes in inhibition status across their early years (Degnan \& Fox, 2007). Unfortunately, since BI was not assessed at the current study follow up, we are unable to resolve this issue. 
The absence of a relationship between insecure infant attachment and children's anxiously negative DP responses, while possibly seeming to diverge from previous research (e.g., Oppenheim, 1997) needs to be considered in the light of the assessments involved. Thus, the current study DP was designed to assess child responses to a specific, imminent, socially challenging event, in which the mother figure was absent from three of the four scenarios presented. This stands in contrast to the more generalized attachment-based story stems (e.g., the MSSB), in which representations of parents play a central role throughout. Further, although attachment studies have found associations between infant security and children's subsequent social relationships, these are mainly found where relationships are intimate (Belsky \& Fearon, 2008), rather than the relationships with unfamiliar people, as largely depicted in the current DP stems. It is also important to note that, in the current study, maternal social phobia was not associated with child attachment insecurity. This finding is consistent with other results for this sample showing that, in contexts free of social threat, socially anxious mothers are as sensitive and warm to their children as non-anxious mothers (Murray et al., 2007; Murray, Lau, Arteche, Creswell, Russ et al., 2012), suggesting that insecurity is not necessarily a route via which social anxiety is transmitted from mother to child.

A key aspect of our DP assessment and associated coding scheme was that we included a range of scenarios designed to elucidate a variety of features of child social anxiety, including performance negativity, negative expectations of others' evaluations, and social avoidance, as well as indices of more general anxiety, such as threat interpretation bias and over-dependence on the mother. Such child cognitive responses comprised the core, and most frequent, elements of our measure of child anxious negativity. However, in order to arrive at a comprehensive characterization of the child's account, in common with other DP methods (Oppenheim, 1997), we also included more affective expressions and narrative 
process dimensions (e.g., manifest anxious behavior, reluctance or refusal to discuss the school topic). While this inclusive strategy has the advantage of capturing a range of important aspects of child functioning and potential vulnerability to social anxiety, our resultant summary measure of DP anxious negativity necessarily limits understanding of the role of the individual components, as each was captured by only one, or a small number of response codes. To the extent, therefore, that researchers wish to identify the role of discrete cognitive and affective components in contributing to child vulnerability and subsequent anxiety (e.g., threat interpretation $v s$. negative self-evaluation $v s$. avoidance), use of even more focused DP codes may be required. On the other hand, while a potential strength of our design for elucidating child vulnerability in the context of maternal social anxiety was its focus on a social challenge, we were not able to address the question of the specificity of this effect, and whether the children of socially anxious mothers would have manifested similar vulnerability in the face of more general DP stems. Again, where this rather different question is being addressed from the one posed in the current study, additional, in this case, non-social, DP stems may be needed. Similarly, one cannot know from the current study whether children of mothers with non-social forms of anxiety might have shown the same profile of DP anxious negativity as found for children of mothers with social phobia, and, therefore, whether our findings reflect the influence of maternal social anxiety in particular, or maternal anxiety in general. It would be of great interest to further explore the value of such DP methods in elucidating vulnerability for other specific disorders, similarly using disorder-relevant themes (e.g., issues of contamination/checking in children at risk for obsessive-compulsive disorder).

Some study limitations should be noted. In particular, the composition of the sample (mostly high SES, Caucasian families) limits the generalizability of our findings. Given these family demographics, it is possible that our findings may underestimate the influence of 
maternal social phobia, as research generally shows stronger effects of maternal psychopathology in the context of adversity (e.g., Sinclair \& Murray, 1998). The fact that we recruited a community, rather than clinic sample, may also mean that our findings provide a somewhat conservative estimate of the associations between maternal social phobia and child DP responses. Most index mothers did not retain a social phobia diagnosis for the entire duration of the follow-up, yet we found that these mothers continued to experience significantly elevated social anxiety symptoms, and that the children of these 'sub-clinical' mothers also showed significantly more anxiously negative DP than control group children. Nevertheless, more detailed consideration of the effects of the timing of the maternal disorder, which was beyond the scope of our study, would be desirable.

A second limitation concerned the duration of follow-up. Thus, previous research suggests that child cognitions as accessed by DP techniques may be implicated in the short term (i.e., 12 months) development of anxiety, but not the longer term maintenance of disorder (Dodd et al., 2011). Our data cannot address this issue, and while our findings support the hypothesis that children's DP responses can indicate a precursor to anxiety, further investigation of this sample at a later developmental stage would be required to establish their full significance. Finally, as the great majority of mothers in this sample were co-habiting, there may be a sizable paternal influence that was not measured. Investigation of both mother and father characteristics would enhance future work. 


\section{References}

Achenbach, T. M., \& Rescorla, L. A. (2000). Manual for the ASEBA preschool forms and profiles. Burlington, USA: University of Vermont, Research Center for Children, Youth, \& Families.

Ainsworth, M. D. S., Blehar, M. C., Waters, E., \& Wall, S. (1978). Patterns of attachment: A psychological study of the strange situation. Hillsdale, New Jersey: Erlbaum.

Arend, R., Gove, F. L., \& Sroufe, A. L. (1979). Continuity of individual adaptation from infancy to kindergarten: a predictive study of ego-resilience and curiosity in preschoolers. Child Development, 50(4), 950-959.

Alvarez, A., \& Phillips, A. (1998). The importance of play: A child psychotherapist's view. Child Psychology \& Psychiatry Review, 3(3), 99-103.

Barrett, P. M., Rapee, R. M., Dadds, M. M., \& Ryan, S. M. (1996). Family enhancement of cognitive style in anxious and aggressive children. Journal of Abnormal Child Psychology, 24(2), 187-203.

Beidel, D. C., \& Turner, S. M. (1998). Shy children, phobic adults: Nature and treatment of social phobia. Washington: American Psychological Association.

Belsky, J., Hsieh, K., \& Crnic, K. (1998). Mothering, fathering, and infant negativity as antecedents of boys' externalizing problems and inhibition at age 3 years: Differential susceptibility to rearing experience? Development and Psychopathology, 10, 301-319.

Belsky, J., \& Fearon, R. M. P. (2008). Precursors of attachment security. In J. Cassidy \& P. R. Shaver (Eds.), Handbook of Attachment Theory and Research (2nd ed.). Guildford: Guildford Press.

Bettmann, J. E., \& Lundahl, B. W. (2007). Tell me a story: A review of narrative assessments for preschoolers. Child and Adolescent Social Work, 24, 455-475. 
Bretherton, I., \& Oppenheim, D. (2003). The MacArthur story stem battery: Development, administration, reliability, validity, and reflections about meaning. In R. N. Emde, D. P. Wolf \& D. Oppenheim (Eds.), Revealing the Inner Worlds of Young Children: The MacArthur Story Stem Battery and Parent-Child Narratives. Oxford: Oxford University Press.

Carter, A., Briggs-Gowan, M. J., \& Ornstein Davis, N. (2004). Assessment of young children's social-emotional development and psychopathology: recent advances and recommendations for practice. Journal of Child Psychology and Psychiatry, 45(1), 109-134.

Cartwright-Hatton, S., McNicol, K., \& Doubleday, E. (2006). Anxiety in a neglected population: Prevalence of anxiety disorders in pre-adolescent children. Clinical Psychology Review, 26, 817-833.

Cooper, P. J., Fearn, V., Willetts, L., Seabrook, H., \& Parkinson, M. (2006). Affective disorder in the parents of a clinic sample of children with anxiety disorders. Journal of Affective Disorders, 93, 205-212.

Degnan, K. A., Almas, A. N., \& Fox, N. A. (2010). Temperament and the environment in the etiology of childhood anxiety. Journal of Child Psychology and Psychiatry, 51(4), 497-517.

Degnan, K. A., \& Fox., N. A. (2007). Behavioral inhibition and anxiety disorders: Multiple levels of a resilience process. Development and Psychopathology, 19, 729746.

Degonda M., \& Angst, J. (1993) The Zurich study XX. Social Phobia and agoraphobia European Archives of Psychiatry and Clinical Neuroscience, 243, 95-102. 
Ding, S. (2005). Introduction: children's personal and social development. In S. Ding \& K. Littleton (Eds.), Children's personal and social development. Milton Keynes: The Open University.

Dodd, H. F., Hudson, J. L., Morris, T. L., \& Wise, C. K. (2011). Interpretation bias in preschool children at risk for anxiety: A prospective study. Journal of Abnormal Psychology, 121(1), 28-38.

Farrington, D. P., \& Loeber, R. (2000). Some benefits of dichotomization in psychiatric and criminological research. Criminal Behaviour and Mental Health, 10, 100-122.

First, M. B., Spitzer, R. L., Gibbon, M., \& Williams, J. B. W. (2002). Structured Clinical Interview for DSM-IV-TR Axis I Disorders, Research Version, Patient Edition. New York: Biometrics Research, New York State Psychiatric Institute.

Hane, A., Cheah, C., Rubin, K., \& Fox, N. (2008). The role of maternal behavior in the relation between shyness and social withdrawal in early childhood and social withdrawal in later childhood. Social Development, 17, 795-811

Hettema, J.M., Neale, M.C., \& Kendler, K.S. (2001). A review and metaanalysis of the genetic epidemiology of anxiety disorders. American Journal of Psychiatry, 158, $1568-1578$.

Hill, J., Fonagy, P., Lancaster, G., \& Broyden, N. (2007). Aggression and intentionality in narrative responses to conflict and distress story stems: An investigation of boys with disruptive behaviour problems. Attachment \& Human Development, 9(3), 223-237.

HMSO. (2005). The National Statistics Socio-economic Classification User Manual. In The Office for National Statistics (Ed.). Basingstoke: Palgrave MacMillan.

Holmberg, J., Robinson, J. L., Corbitt-Price, J., \& Wiener, P. (2007). Using narratives to assess competencies and risks in young children: Experiences with high risk and normal populations. Infant Mental Health Journal, 28(6), 647-666. 
Kagan, J., Snidman, N., Zentner, M., \& Peterson, E. (1999). Infant temperament and anxious symptoms in school age children. Development and Psychopathology, 11, 209-224.

Kendall, P. C. (2006). Guiding theory for therapy with children and adolescents. In P. C. Kendall (Ed.), Child and adolescent therapy: Cognitive-behavioral procedures (3rd ed., pp. 3-32). New York: Guilford Press.

Laible, D., Carlo, G., Torquati, J., \& Ontai, L. (2004). Children's perceptions of family relationships as assessed in a Doll Story Completion Task: Links to Parenting, Social Competence, and Externalizing behavior. Social Development, 13(4), 551-569.

Lieb, R., Wittchen, H.-U., Hofler, M., Fuetsch, M., Stein, M. B., \& Merikangas, K. R. (2000). Parental psychopathology, parenting styles, and the risk of social phobia in offspring. Archives of General Psychiatry, 57, 859-866.

Main, M., \& Solomon, J. (1990). Procedures for identifying infants as disorganized/disoriented during the Ainsworth Strange Situation. In M. T. Greenberg, D. Cicchetti \& E. M. Cummings (Eds.), Attachment in the preschool years. Chicago: University of Chicago Press.

Marshall, P., \& Katz, L. L. (1992). Children in clinical settings. In J. Garbarino \& F. M. Stott (Eds.), What children can tell us: Eliciting, interpreting, and evaluating critical information from children (pp. 247-265). San Francisco: Jossey-Bass.

Mattick, R. P., \& Clarke, J. C. (1998). Development and validation of measures of social phobia scrutiny fear and social interaction anxiety. Behaviour Research and Therapy, $36(4), 455-470$.

Murray, L., Cooper, P. J., Creswell, C., Schofield, E., \& Sack, C. (2007). The effects of maternal social phobia on mother-infant interactions and infant social responsiveness. Journal of Child Psychology and Psychiatry, 48(1), 45-52. 
Murray, L., de Rosnay, M., Pearson, J., Bergeron, C., Schofield, E., Royal-Lawson, M., et al. (2008). Intergenerational transmission of social anxiety: The role of social referencing processes in infancy. Child Development, 79(4), 1049-1064.

Murray, L., Lau, P. Y., Arteche, A., Creswell, C., Russ, S., Zoppa., L. D., Muggeo, M., Stein, A. \& Cooper, P. J. (2012). Parenting by anxious mothers: effects of disorder subtype, context and child characteristics. Journal of Child Psychology and Psychiatry, 53(2), 188-196.

Murray, L., Woolgar, M., Briers, S. \& Hipwell, A. (1999b). Childrens' social representations in dolls' house play and theory of mind tasks, and their relation to family adversity and child disturbance. Social Development, 8(2), 179-200.

Najman, J. M., Williams, G. M., Nikles, J., Spence, S. H., Bor, W., O'Callaghan, M., et al., (2001). Bias influencing maternal reports of child behaviour and emotional state. Social Psychiatry and Psychiatric Epidemiology, 36(4), 186-194.

Oppenheim, D. (1997). The Attachment Doll-play Interview for preschoolers. International Journal of Behavioral Development, 20(4), 681-697.

Pina, A. A., Silverman, W. K., Saavedra, L. M., \& Weems, C. F. (2001). An analysis of the RCMAS lie scale in a clinic sample of anxious children. Anxiety Disorders, 15, 443457.

Rapee, R. M., Schniering, C. A., \& Hudson, J. L. (2009). Anxiety disorders during childhood and adolescence: origins and treatment. Annual Review of Clinical Psychology, 5, 1141.

Ramchandani, P., Murray, L., Romano, G., Vlachos, H., \& Stein, A. (2011). An investigation of health anxiety in families where children have recurrent abdominal pain. Journal of Pediatric Psychology, 36, 409-419. 
Schreier, A., Wittchen, H-U., Hofler, M., \& Lieb, R. (2008). Anxiety disorders in mothers and their children: prospective longitudinal community study. The British Journal of Psychiatry, 192, 308-309.

Sinclair, D., \& Murray, L. (1998). Effects of postnatal depression on children's adjustment to school. Teacher reports. The British Journal of Psychiatry, 172, 58-63.

Spence, S. H. (1995). Social skills training: Enhancing social competence with children and

adolescents- Research and technical supplement. Windsor: NFER-NELSON Ltd.

Warren, S. L., Emde, R. N., \& Sroufe, L. A. (2000). Internal representations: Predicting anxiety from children's play narratives. Journal of the American Academy of Child and Adolescent Psychiatry, 39(1), 100-107.

Warren, S. L., Oppenheim, D., \& Emde, R. N. (1996). Can emotions and themes in children's play predict behaviour problems? Journal of the American Academy of Child and Adolescent Psychiatry, 34(10), 1331-1337.

Wechsler, D. (1990). Wechsler Pre-school \& Primary Scale of Intelligence-Revised (WPPSIR) (UK ed.). Sidcup: Psychological Corporation.

Wittchen, H., \& Fehm, L. (2003). Epidemiology and natural course of social fears and social phobia. Acta Psychiatrica Scandinavica, 108(Suppl. 417), 4-18.

Woolgar, M. (1999). Projective doll play methodologies for preschool children. Child Psychology and Psychiatry Review, 4, 126-134 
Table 1: Demographic Characteristics by Group

\begin{tabular}{|c|c|c|}
\hline & $\begin{array}{l}\text { Control group } \\
(\max N=60)\end{array}$ & $\begin{array}{l}\text { Social phobia group } \\
(\max N=62)\end{array}$ \\
\hline Maternal SES: high & $40(71.7 \%)$ & $47(69.4 \%)$ \\
\hline Family ethnicity: Caucasian & $59(98.3 \%)$ & $62(100 \%)$ \\
\hline Married/co-habiting & $60(100 \%)$ & $59(95.2 \%)$ \\
\hline $\begin{array}{l}\text { Maternal age (yrs) at child's birth: } \\
\text { mean (SD) }\end{array}$ & $31.58(3.73)$ & $31.19(4.87)$ \\
\hline $\begin{array}{l}\text { SPS for full DP sample } \\
\text { for non-diagnostic SP group }\end{array}$ & $\begin{array}{l}7.32(7.89) \\
\text { ،" }\end{array}$ & $\begin{array}{l}22.22(14.51) \\
17.18(9.92)\end{array}$ \\
\hline $\begin{array}{l}\text { SIAS for full DP sample } \\
\text { for non-diagnostic SP group }\end{array}$ & $13.08(7.00)$ & $\begin{array}{l}37.80(13.87) \\
31.65(10.81)\end{array}$ \\
\hline Child gender: male & $28(46.7 \%)$ & $27(43.5 \%)$ \\
\hline Birth order: $1^{\text {st }}$ born & $46(76.7 \%)$ & $39(62.9 \%)$ \\
\hline BI: high & $14(24.1 \%)$ & $17(27.9 \%)$ \\
\hline Attachment: insecure & $17(29.8 \%)$ & $17(28.3 \%)$ \\
\hline Child age at DP(mths): Mean (SD) & $54.31(3.02)$ & $54.47(2.65)$ \\
\hline Child verbal IQ: Mean (SD) & $57.11(7.83)$ & $57.15(9.79)$ \\
\hline
\end{tabular}


Table 2: Maternal Social Anxiety Group Predicting Doll Play, Controlling for Sex

\begin{tabular}{|c|c|c|c|c|}
\hline \multicolumn{5}{|c|}{ Logistic regression analyses } \\
\hline & $\mathrm{B}(\mathrm{SE})$ & Wald & Odds Ratio & $95 \% \mathrm{CI}$ for OR \\
\hline \multicolumn{5}{|l|}{ Model 1} \\
\hline Constant & $-1.63(0.33)$ & $24.35 * *$ & 0.20 & \\
\hline Sex & $0.99(0.44)$ & $5.16^{*}$ & 2.69 & $1.15-6.30$ \\
\hline \multicolumn{5}{|l|}{ Model 2} \\
\hline Constant & $-2.20(0.45)$ & $23.37 * *$ & 0.11 & \\
\hline Sex & $1.06(0.45)$ & $5.62 *$ & 2.88 & $1.20-6.90$ \\
\hline Group & $0.95(0.45)$ & $4.35^{*}$ & 2.57 & $1.06-6.26$ \\
\hline
\end{tabular}

Note: Model 1: $\chi^{2}(1)=5.36, \mathrm{p}<.05, \mathrm{R}^{2}=.06$ (Nagelkerke)

Model $2: \chi^{2}(2)=9.94, p<.01, R^{2}=.12$ 


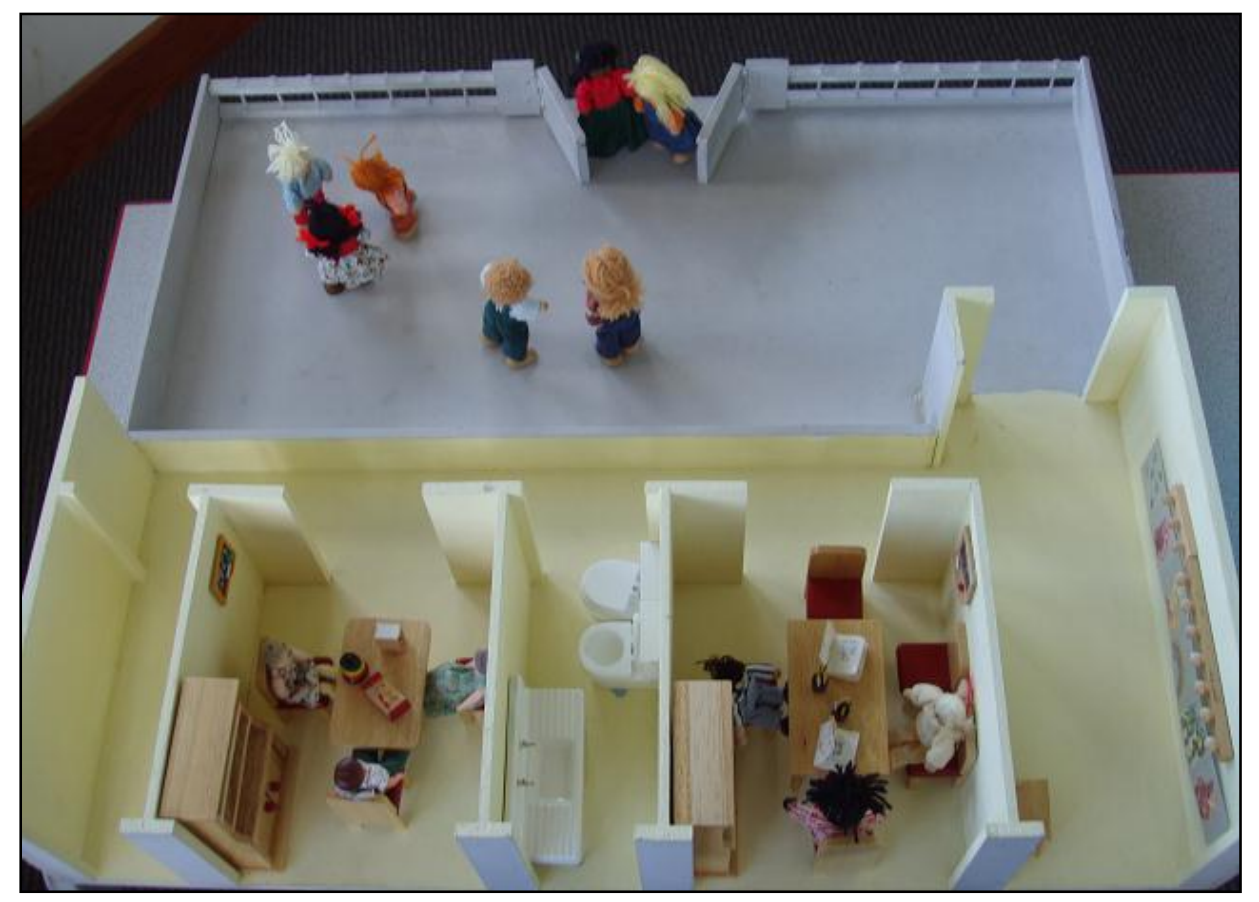

Figure 1: Model school DP set up 
Key points:

- Accessing young children's beliefs and expectations can be difficult, but Doll Play may be a useful tool to examine young children's experiences.

- This study used a disorder specific context (starting school) to examine the association between maternal social anxiety, child Doll Play responses, and actual child school-based anxiety.

- Children of socially anxious mothers showed greater anxious negativity in their Doll Play responses to starting school than children of control mothers.

- Child Doll Play responses predicted teacher-reported child school-based anxiety, even after controlling for baseline anxiety.

- Further work is needed to streamline this tool for clinical assessment and intervention work. 